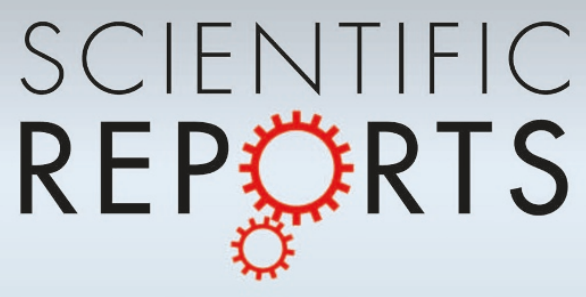

\section{OPEN}

\section{SUBJECT AREAS:}

PATHOGENS

ANTIBIOTICS

BIOMIMETIC SYNTHESIS

ANTIMICROBIAL RESISTANCE

Received

2 December 2014

Accepted

23 February 2015

Published

18 March 2015

Correspondence and requests for materials should be addressed to

A.M. (amor@tx. technion.ac.il)

\title{
Sensitization of Gram-negative bacteria to rifampin and OAK combinations
}

\author{
Joanna Jammal, Fadia Zaknoon, Galoz Kaneti, Keren Goldberg \& Amram Mor
}

Department of Biotechnology \& Food Engineering, Technion-lsrael Institute of Technology, Haifa 32000, Israel.

While individually inefficient against Gram-negative bacteria, in-vitro combinations of rifampin and OAK were mutually synergistic since sub-minimal inhibitory concentrations of one compound have potentiated the other by 2-4 orders of magnitude. Synergy persisted in-vivo as single-dose systemic treatment of Klebsiella infected mice resulted in $10-20 \%$ versus $60 \%$ survival, respectively accomplished by individual and combined compounds. This outcome was achieved without drug formulation, rather, pharmacokinetic considerations have inspired the therapeutic regimen.

$\mathrm{T}$ he spread of multidrug resistance (MDR) among pathogenic bacteria continues to challenge modern medicine. In particular, shortage in new antibiotics for treating Gram-negative bacteria (GNB) infections is disquieting, stressing a growing urgency for alternative solutions ${ }^{1-4}$. Oligo-acyl-lysyls (OAKs) represent a potentially useful approach for developing safe, efficient and economically viable antimicrobial small molecules to meet the global and ever increasing MDR-associated threats ${ }^{5-7}$. Previously, the prototypical OAK sequence acyl-lysyl-lysyl-aminoacyl-lysyl proved to generate OAK derivatives targeting Gram-positive bacteria (GPB) ${ }^{8,9}$ and more recently, prompted inefficient antibiotics to improve activity against $\mathrm{GNB}^{10}$. Superficial OAK interactions with both the cytoplasmic and outer membrane (CM and OM, respectively, Fig. 1a) were implicated in this chemo-sensitization property, causing naturally resistant bacteria to become sensitive to formerly inactive antibiotics ${ }^{10}$ or to overcome acquired resistance mechanisms ${ }^{11}$.

Here, we challenged these putative OAK-membrane interactions by testing their capacity to mediate uptake of otherwise excluded antibiotics, such as rifampin ${ }^{12}$. Various similar studies were conducted using a panoply of chemicals entities ${ }^{13-16}$ ranging from cation-chelators to host defense peptides, highlighting the potential usefulness of these combinations that may provide future therapeutic alternatives to GNB infections, albeit not always without dispute ${ }^{17}$. Rifampin and penicillin are hydrophobic antibiotics, respectively targeting cytoplasmic and periplasmic bacterial components. As inactivity of penicillin on GNB is often due to $\beta$-lactam processing enzymes, its periplasmic accumulation is not expected to benefit from OAK's action, unlike rifampin whose inefficacy over GNB usually results from its natural low OM-permeability ${ }^{12,18}$, although other mechanisms were reported to confer additional resistance to rifampin, including mutations in RNA polymerase gene, $r p o B^{19,20}$. Note that rifampin (member of the rifamycin family) is a highly effective anti-mycobacterial drug, even though the mycobacterial outer membrane hinders, to some extent, its entry. Only in several mycobacteria species this reduced permeability results in variable degrees of resistance ${ }^{21,22}$.

\section{Results}

Minimal inhibitory concentration (MIC) assays demonstrated that OAKs and antibiotics were individually unable to efficiently inhibit growth of GNB, whereas rifampin became extremely potent in presence of subMIC of the reference OAK $C_{12(\omega 7)} \mathrm{X}$ (Structure shown in Fig. 1b). Figure 2a illustrates the case of E. coli while Supplementary Fig. S1 (Supplementary Results online) summarizes data obtained with three additional species representing medically relevant GNB, collectively revealing the extent to which rifampin's MIC was reduced in presence of sub-MIC OAK. Similar data obtained with erythromycin ${ }^{10}$ is included for comparison.

Remarkably, sub-MIC levels of rifampin or erythromycin have also potentiated the OAK's antibacterial activity against E. coli, reducing the MIC from $>50$ down to $<1 \mu \mathrm{g} / \mathrm{ml}$ (Fig. 2b). Supplementary Fig. S2 shows that similar outcome is obtained with additional bacterial strains and species, thereby confirming the occurrence of a mutually synergistic process in GNB. Figure 2c,d suggests that sub-MIC OAK and rifampin might induce membrane depolarization at micromolar concentrations, while underlining significant differences in terms of dose and kinetics (mechanistic relevance is discussed below). 


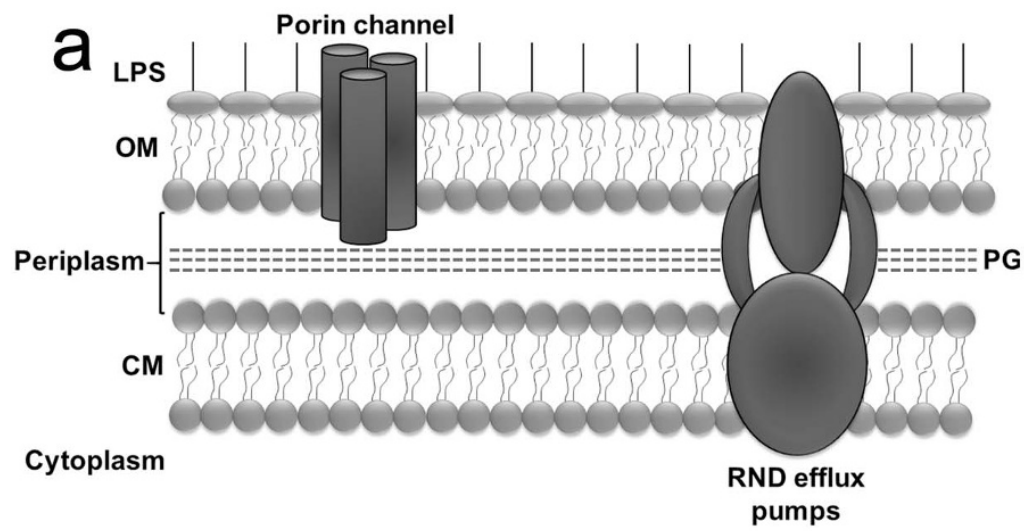

b

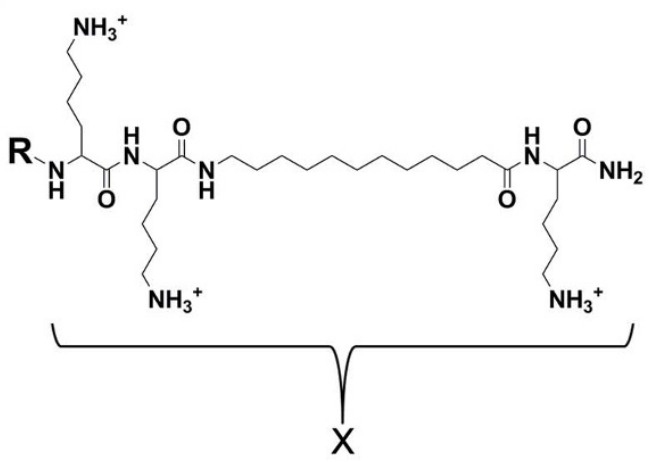

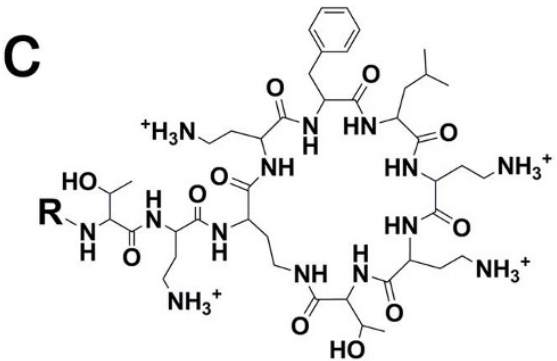

Figure 1 Structural features of bacterial cell wall and lipopeptides. (a) Typical double-membrane organization in Gram-negative bacteria. The outer membrane (OM) is composed of proteins bathing in lipids such as lipoplysaccharides (LPS) in the outermost layer and phospholipids in the inner layer whereas the cytoplasmic membrane (CM) is composed of phospholipids and proteins in both layers. The space between OM and CM (the periplasm) contains a thin peptidoglycan (PG) layer. The protein complex passing through both membranes represents a resistance-nodulation-division efflux pump. (b) Molecular structures of OAKs investigated, referred to as RX, where R is either $\mathrm{H}$ or one of the following acyls: octanoyl $\left(\mathrm{C}_{8}\right)$, decanoyl $\left(\mathrm{C}_{10}\right)$, dodecanoyl $\left(\mathrm{C}_{12}\right)$ or its unsaturated version dodecenoyl $\left(\mathrm{C}_{12(\omega 7)}\right)$ and $\mathrm{X}$ is the amino acid sequence lysyl-lysyl-aminododecanoyl-lysyl-amide $\left(\mathrm{KKC}_{12} \mathrm{~K}\right)$. (c) Structure of polymyxin where $\mathrm{R}$ is 6-methyloctanoyl-diaminobutiroyl or $\mathrm{H}$, for the native polymyxin $\mathrm{B}$ and nonapeptide derivative, respectively.

Table 1 summarizes the biophysical attributes of OAK derivatives, including published data concerning two derivatives whose $\mathrm{N}$-terminal dodecenoyl was replaced with a saturated version $\left(\mathrm{C}_{12} \mathrm{X}\right)$ or deleted $^{6,9,23}$, indicating that the hydrophobic analog undergoes selfassembly at lower concentrations and is more efficient in hemolysis and antibacterial activities. As evident from the middle part of Table 1, this analog was as potent as $\mathrm{C}_{12(\omega 7)} \mathrm{X}$ in sensitizing E.coli to rifampin. These properties were diminished in absence of the $\mathrm{N}$ terminal acyl, as expected for excessively hydrophilic $\mathrm{OAKs}^{5,6}$, raising the question of how the OAK would behave if the N-terminal acyl was replaced with analogs having intermediate hydrophobicity values. We therefore produced two new derivatives, $\mathrm{C}_{10} \mathrm{X}$ and $\mathrm{C}_{8} \mathrm{X}$, which revealed rather intriguing biological profiles: they were less active in hemolytic and antibacterial tests but they sensitized bacteria to rifampin, nonetheless. As shown in Supplementary Table S1, sensitization persisted against different species, thereby establishing $\mathrm{C}_{10} \mathrm{X}$ as a potent sensitizer of GNB to rifampin since it reduced active concentrations from high micromolar- to low nanomolar-range. Note that $\mathrm{C}_{10} \mathrm{X}$ also displayed reciprocal synergism with rifampin (Supplementary Fig. S3) as observed for the reference OAK, whereas these OAKs were unable to sensitize the tested bacteria to penicillin.

Figure 2e,f shows preliminary toxicity and pharmacokinetic data. Oral administrations of OAKs were well tolerated, the maximal tolerated dose (MTD) being $>20 \mathrm{mg} / \mathrm{Kg}$, but this dose-range did not

Table 1 | Structure-activity study highlighting biophysical attributes of $\mathrm{N}$-terminal OAK derivatives

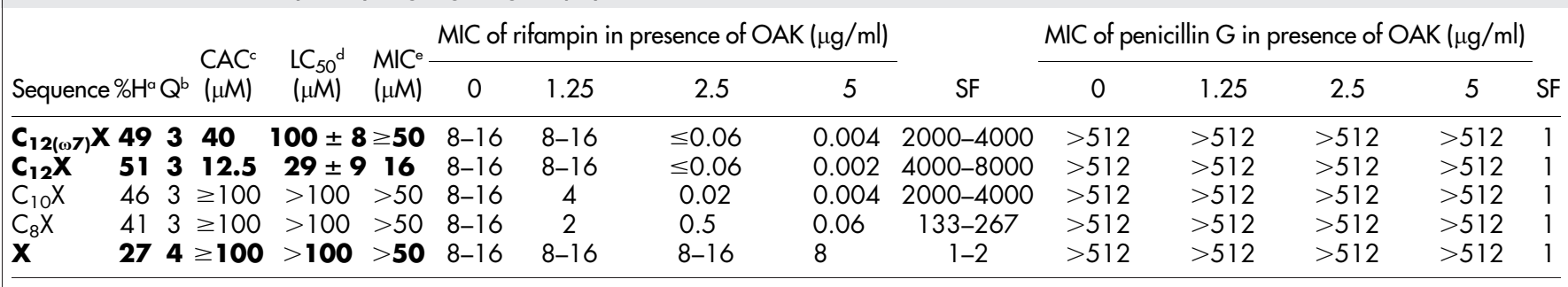

$\mathrm{X}=$ lysyl-lysyl-aminododecanoyl-lysyl-amide;

aHydrophobicity measure, defined as \% acetonitrile eluent in $\mathrm{C}_{18} \mathrm{HPLC}$ column

bMolecular charge in physiological conditions;

${ }^{\circ}$ Critical aggregation concentration in PBS;

¿OAK concentration that induced $50 \%$ hemolysis after $3 \mathrm{~h}$ incubation in PBS $37^{\circ} \mathrm{C}$;

eTested against $E$. coli strain ML-35p. SF, sensitization factor defined as the ratio of the MIC in absence of OAK to that in presence of $5 \mu \mathrm{g} / \mathrm{ml}$ of OAK. Bold lines indicate published data. 

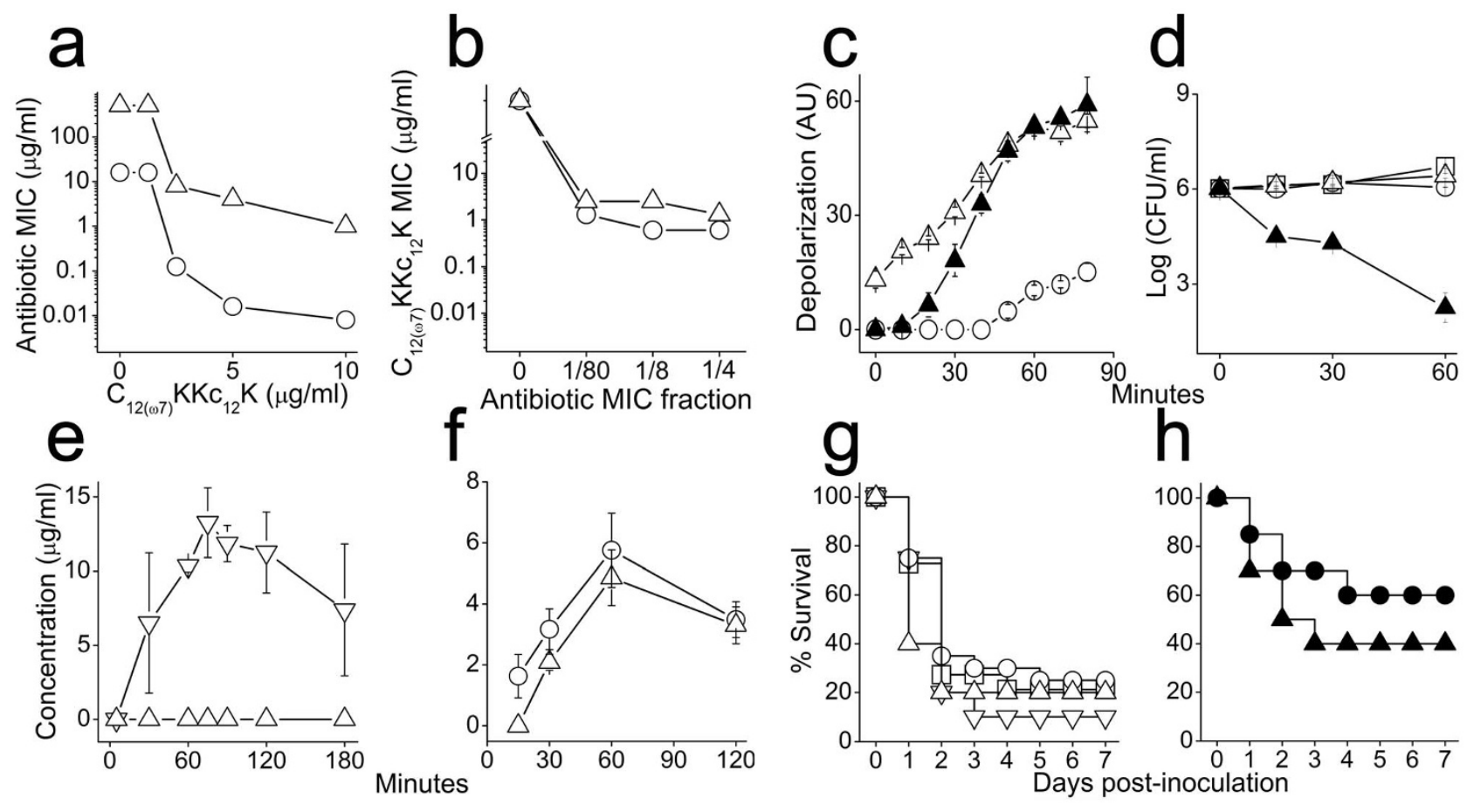

Figure 2 Evidence for sensitization of $E$. coli to antibiotics and OAKs combinations. Panels (a,b) respectively show the MIC evolution when bacteria were treated with rifampin (circles) or erythromycin (triangles) in presence of the specified sub-MIC OAK and vice versa. OAK MIC against this strain is $>50 \mu \mathrm{g} / \mathrm{ml}$ (panel a). For Panel b, the standalone antibiotic MIC is 16 and $512 \mu \mathrm{g} / \mathrm{ml}$, respectively for rifampin and erythromycin. Panels (c,d) show the time-dependence of membrane depolarization and the bacterial viability during the experiment, respectively. Symbols: squares, untreated control; circles, rifampin $(4 \mu \mathrm{g} / \mathrm{ml})$; open triangles, OAK $(1.3 \mu \mathrm{g} / \mathrm{ml})$; solid triangles, OAK + rifampin. Panels $(\mathrm{e}, \mathrm{f})$ show a pharmacokinetic study using LC/MS analysis to monitor the mean plasma concentrations of $\mathrm{C}_{12(\omega 7)} \mathrm{X}$ (triangles) and rifampin (inverted triangles) after oral administration of $20 \mathrm{mg} / \mathrm{Kg}$ each, calculated based on their respective calibration curves (e) and the same analysis for subcutaneous administrations of $\mathrm{C}_{12(\omega 7)} \mathrm{X}\left(\right.$ triangles) and $\mathrm{C}_{10} \mathrm{X}$ (circles) at $12.5 \mathrm{mg} / \mathrm{Kg}$ each (f). Error bars = s.d. Panels (g,h) show systemic efficacy in neutropenic mice after monotherapy (g) and combination therapy (h). Symbols: open squares, vehicle treated control; triangles, $\mathrm{C}_{12(\omega 7)} \mathrm{X}$ alone; circles, $\mathrm{C}_{10} \mathrm{X}$ alone; inverted triangles, rifampin alone; solid triangles, combined treatment of $\mathrm{C}_{12(\omega)} \mathrm{X}$ and rifampin; solid circles, combined treatment of $\mathrm{C}_{10} \mathrm{X}$ and rifampin. The data represent averages from two independent experiments performed with 10 mice/group (standard deviations were $<10 \%$ ).

allow detectable amounts to reach the blood compartment, unlike rifampin that rapidly accumulated up to $13.26 \pm 2.25 \mu \mathrm{g} / \mathrm{ml}$ (nearly as reported $)^{24,25}$. In contrast, subcutaneous OAKs administrations (MTD > $20 \mathrm{mg} / \mathrm{Kg}$ ) were both well tolerated and enabled plasma levels of around $5 \mu \mathrm{g} / \mathrm{ml}$ when dosed at $12.5 \mathrm{mg} / \mathrm{Kg}$. Consequently, to promote optimal/simultaneous blood concentrations during efficacy tests, we opted for subcutaneous OAKs administration- one hour after rifampin's oral administration. To test the drugs ability to affect disease course systemically, we used neutropenic mice to nullify neutrophil-mediated immune contributions in resolving bacterial infections ${ }^{26}$. Inoculation with $K$. pneumoniae followed by vehicle treatment, resulted in rapid death of most mice $(20 \pm 10 \%$ survival) within 1-2 days (Fig. $2 \mathrm{~g}$ ). Under these conditions, single dose treatments with rifampin, $\mathrm{C}_{12(\omega 7)} \mathrm{X}$ or $\mathrm{C}_{10} \mathrm{X}$, were unable to significantly improve the survival rates, as they yielded 10, 20 and $25 \%$ survivors at day 7 ( $P<0.004,<0.07$ and $<0.002$, respectively). Administration of rifampin combined with $\mathrm{C}_{12(\omega 7)} \mathrm{X}$ increased mice survival from 20 to $40 \%$ ( $P<0.003$, Fig. $2 \mathrm{~h})$, while replacing the reference $\mathrm{OAK}$ with $\mathrm{C}_{10} \mathrm{X}$ has further increased the survival rate to $60 \%(P<0.0004$, Fig. $2 \mathrm{~h})$.

To shed light into the molecular basis for the observed synergy, we first utilized an assay capable of differentiating permeability changes in $\mathrm{CM}$ and $\mathrm{OM}$ by testing the leakage of small molecules in the engineered E. coli strain, ML-35p $\mathrm{p}^{27}$ (a kind gift from Prof. Richard Epand, McMaster University, Canada). The OM became permeable at various sub-MIC values (Fig. 3a) but $\mathrm{C}_{10} \mathrm{X}$ exhibited higher potency than $\mathrm{C}_{12(\omega 7)} \mathrm{X}$ and was equipotent with polymyxin $\mathrm{B}$, considered gold standard reference for OM permeabilization ${ }^{13,28-30}$. At the concentrations used (which were higher than the MIC for polymyxin), the compounds did not premeabilize the CM, except for $\mathrm{C}_{12} \mathrm{X}$ that incidentally, was also more potent than its unsaturated analog (Fig. 3b).

To verify whether the peptides OM permeabilization ability involved similar binding affinities to lipopolysaccharides (LPS), we used the dansyl-polymyxin assay ${ }^{31}$. Supplementary Fig. S4 summarizes the dose-dependent kinetics obtained with LPS from two GNB (E. coli and P. aeruginosa). Figure $3 c$ shows that OAKs affinity increased with increasing hydrophobicity (Table 1) but the OAKs exhibited a significantly lower affinity than polymyxin B. For instance, about 10-fold difference was observed with $\mathrm{C}_{10} \mathrm{X}(\mathrm{P}<$ $0.004)$. Finally, time-kill kinetics obtained at synergistic concentrations (Fig. 3d,e) with OAK alone and in presence of the biocidal rifampin or the biostatic erythromycin, indicated that after a brief delay, normal bacterial growth has resumed upon exposure to sub-MIC $\mathrm{C}_{12(\omega 7)} \mathrm{X}$. This delay was not observable with $\mathrm{C}_{10} \mathrm{X}$ (Supplementary Fig. S5), indicating that this more hydrophilic analog, just like erythromycin or rifampin, did not affect the normal growth rates, only their combination with an OAK did. Moreover, synergism vanished if rifampin and OAKs were not added simultaneously: For example, bacterial survival was nearly normal if rifampin addition was delayed by $15 \mathrm{~min}$ after the OAKs (Fig. $3 \mathrm{f}$ ) and vice versa $\left(\mathrm{C}_{10} \mathrm{X}\right.$ is shown in Supplementary Fig. S5).

\section{Discussion}

Rifampin is often used in combination therapy for treating Mycobacterium infections, including tuberculosis and leprosy ${ }^{32,33}$. 

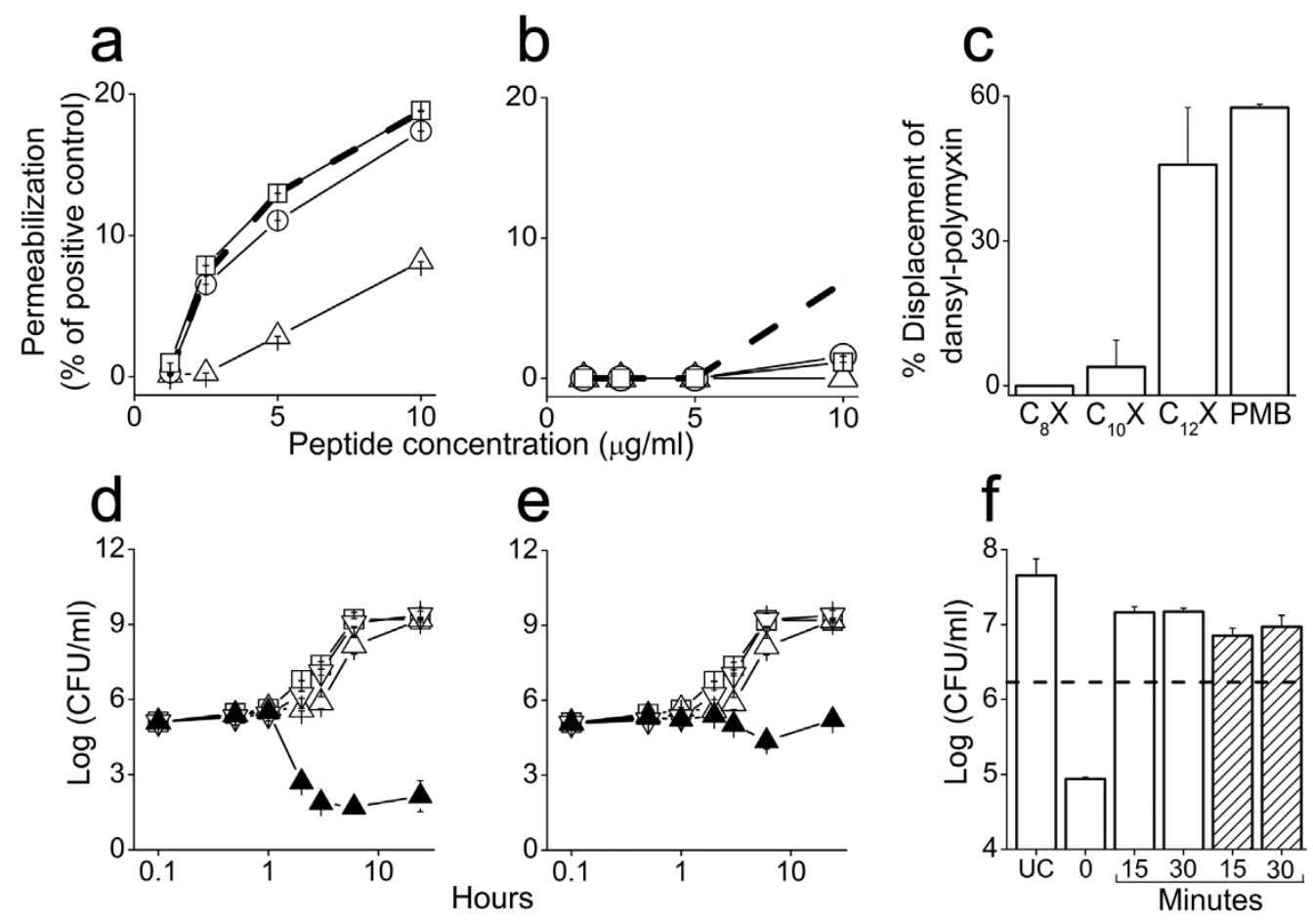

Figure 3 Mechanistic studies. (a,b) Dose-dependent permeabilization of outer and cytoplasmic membranes, respectively, using the E. coli mutant ML$35 p$. Symbols: triangles, $\mathrm{C}_{12(\omega 7)} \mathrm{X}$; circles, $\mathrm{C}_{10} \mathrm{X}$; dashed lines, $\mathrm{C}_{12} \mathrm{X}$; squares, polymyxin B. Dermaseptin $\mathrm{K}_{4} \mathrm{~K}_{20}-\mathrm{S} 4$ (57 $\left.\mu \mathrm{g} / \mathrm{ml}\right)$ was used for full permeabilization of both membranes. (c) Dansyl-polymyxin binding assay performed after pre-incubation ( $1.5 \mathrm{~h}$ at $10 \mu \mathrm{g} / \mathrm{ml}) \mathrm{of} \mathrm{OAKs}$ and polymyxin B with $2 \mu \mathrm{M}$ pure monodansyl-polymyxin and $3 \mu \mathrm{g} / \mathrm{ml}$ LPS from $E$. coli. (d,e) Time-kill kinetics upon bacterial exposure to $\mathrm{C}_{12(\omega 7)} \mathrm{X}$ alone and in combinations with rifampin (d) and erythromycin (e). Symbols: open squares, untreated control; open triangles, $\mathrm{C}_{12(\omega 7)} \mathrm{X}(5 \mu \mathrm{g} / \mathrm{ml})$; inverted open triangles, rifampin or erythromycin ( 0.004 or $0.03 \mu \mathrm{g} / \mathrm{ml}$, respectively); solid triangles, $\mathrm{C}_{12(\omega 7)} \mathrm{X}+$ antibiotic. (f) Effect of delayed exposure to rifampin or OAK; Bacteria (K. pneumoniae CI 1287) were exposed to both $\mathrm{C}_{12(\omega 7)} \mathrm{X}(5 \mu \mathrm{g} / \mathrm{ml})$ and rifampin $(0.008 \mu \mathrm{g} / \mathrm{ml})$ without delay $(\mathrm{t}=0)$ and after delayed exposure to rifampin (white bars) or OAK (striped bars) by 15 or $30 \mathrm{~min}$ in LB culture medium. CFU counts were determined after additional $3 \mathrm{~h}$ incubation in the culture medium. UC; untreated control. Dashed line indicates the inoculum. Error bars $=$ s.d.

Rifampin is also active on Gram-positive cocci but not on enterobacteriaceae- a large family of GNB that includes common pathogens, such as E. coli, Klebsiella, Salmonella or Pseudomonas. Clearly, the opportunity to expand rifampin's activity spectrum and/or to reduce its adverse effects (e.g., hepatotoxicity), would be welcomed $^{34,35}$. The current work revealed that OAKs have the ability to reduce rifampin's active concentrations by several orders of magnitude. Moreover, this study represents the first report (to our knowledge) of a reciprocal chemo-sensitization (mutual synergism) process of such a magnitude, imparting potency upon two molecular species acting by distinct mechanisms, hence the efforts invested towards understanding the underlying molecular basis.

We first focused on obtaining evidence susceptible to clarify the individual roles in the synergistic pair. The activities exhibited by $\mathrm{C}_{12} \mathrm{X}$ alone, might partly explain the enhanced potency observed upon combination. However, being virtually devoid of antibacterial activity on its own, chemo-sensitization activity associated with $\mathrm{C}_{10} \mathrm{X}$ is a priori unexpected; thus, synergism is achievable with little regard to individual antibacterial capacity. In that sense, the new analogs represent valuable tools for deciphering the mechanism underlying synergy by assigning individual responsibilities of each reactant. The fact that $\mathrm{C}_{10} \mathrm{X}$ was more potent than $\mathrm{C}_{12(\omega 7)} \mathrm{X}$ in permeabilizing the $\mathrm{OM}$ is consistent with the view that hemolysis and antibacterial activities are distinguishable from chemo-sensitization. Hence, by reducing their hydrophobicity, $\mathrm{C}_{10} \mathrm{X}$ and $\mathrm{C}_{8} \mathrm{X}$ may have lost attributes that mediated one type of activity but not the other. Consequently, the data can be interpreted as suggesting that, in principle, each synergistic partner does "his own thing", i.e., $\mathrm{C}_{10} \mathrm{X}$ does not participate in the antibiotic effect (which is the sole responsibility of rifampin) but merely enables rifampin to overcome the obstacle preventing its interaction with RNA polymerase, the OM barrier. The biocidal effect observed upon combining OAK and rifampin (as opposed to biostatic effect with OAK and erythromycin), supports this view. Also supporting this hypothesis is the finding that optimal sensitization of rifampin was reached at $\mathrm{ng} / \mathrm{ml}$ as opposed to $\mu \mathrm{g} /$ $\mathrm{ml}$ for OAKs. These concentration ranges are consistent with the drugs specific and non-specific modes of action, respectively.

The mechanism enabling antibiotics to potentiate the OAKs is less understood. It seems to result from precursor damages exerted by micromolar sub-MIC antibiotics that somehow produce OAKhypersusceptible bacteria. This may occur with rifampin by competing with OAKs for membrane interactions due to its hydrophobic/ cationic characters, as suggested by the sigmoidal shape of the depolarization curve which was observed only at micromolar combinations of OAK-rifampin. The sigmoidal shape disappeared at nanomolar levels of rifampin (data not shown) or upon replacing rifampin with micromolar levels of the porin-gated erythromycin ${ }^{10}$. Notwithstandingly, reciprocal synergism might also occur between erythromycin and OAKs, should these efflux substrates ${ }^{10}$ hamper each other's extrusion by populating the binding pockets of resistance-nodulation-division (RND) pumps ${ }^{36}$. Future studies might clarify this issue.

Of interest is the comparison between OAKs and polymyxins, since these cationic lipopeptides permeabilize the OM with similar potencies (Fig. 3a) despite major differences in chemo-physical attributes (Fig. 1c). OAK derivatives reduced rifampin's MIC by 4000 folds at $5 \mu \mathrm{g} / \mathrm{ml}$ (8000-fold at $10 \mu \mathrm{g} / \mathrm{ml}$, data not shown). Under similar conditions, polymixin B nonapeptide derivatives have reportedly reduced rifampin's MIC by $85-750$ and 250-500 folds, respect- 
ively against $E$. coli and $K$. pneumoniae strains ${ }^{37,38}$. The large difference in sensitization factors suggests that it is not solely due to OM permeabilization, perhaps it is also related to additional factors, including the way each lipopeptide affects the CM structure and function ${ }^{9,10}$. In this regard, polymyxins maybe rather handicapped because of their higher affinity for LPS.

Also, this study showed that certain OAKs enhance the effect of rifampin as already described for other antimicrobials (e.g., defen$\operatorname{sins}^{39}$ ) thus raising the question of eventual OAKs advantages compared to antimicrobials that form pores that may allow a better passage of the antibiotic. The advantages of OAKs and other peptidomimetics $^{40-42}$ over classical antimicrobial peptides and proteins are largely documented in the literature and the structural differences compared to polymyxins are highlighted in Fig. 1b,c and Table 1, including in terms of overall size, chemophysical and structural complexity. Besides these differences, antimicrobials that exert "heavy damages" to bacterial membranes are bactericidal and might not necessarily sensitize to rifampin (or other antibiotics) to a great extent as shown with polymyxin B. There is also an inherent advantage over lytic/bactericidal compounds since the milder action of bacteriostatic compounds such as the OAKs in question, reduces the risk for complications associated with endotoxins release ${ }^{43,44}$.

The question of whether synergism can effectively occur in animals was addressed by comparing the drugs efficacies in rescuing critically ill mice. Our pharmacokinetic data suggest that the relevant drug concentrations are achievable at sub-MTD doses whereas the notion that synergism observed in-vitro could persist in-vivo is supported by the viability outcome (Fig. $2 \mathrm{~h}$ ). Therefore, by intimately linking the pharmacokinetics of small molecules and their reciprocal synergism, this study provides encouraging evidence for the potential medical usefulness of the OAK approach for combating human and animal infectious diseases caused by GNB.

\section{Methods}

Peptide synthesis. The OAKs were prepared in-house by the solid-phase method ${ }^{45}$, applying the Fmoc (9-fluorenylmethyloxycarbonyl) active ester chemistry using automated peptide synthesizer (model 433A; Applied Biosystems, Foster City, CA, USA) as described ${ }^{5}$.

Organization in solution. OAKs self-assembly in solution was assessed by lightscattering measurements. OAKs at initial concentration of $100 \mu \mathrm{M}$ were submitted to serial 2-fold dilutions in phosphate buffered saline (PBS) (10 $\mathrm{mM} \mathrm{Na}_{2} \mathrm{HPO}_{4}$, $150 \mathrm{mM} \mathrm{NaCl}, \mathrm{pH}=7.0$ ) and incubated for $2 \mathrm{~h}$ at room temperature (RT) and light scattering of each dilution was recorded by holding both the excitation and the emission at $400 \mathrm{~nm}$ (slit width, $1 \mathrm{~nm}$ ). The data represent averages of at least two separate recordings.

Bacteria. Gram-negative species tested: Escherichia coli (ML-35p; American Type Culture Collection (ATCC; Manassas,VA, USA) strain: $\beta$-lactamase producer 35218; clinical isolates: 14182, 14384, U16327, U16329), Pseudomonas aeruginosa (CI 11662), Salmonella enterica serovar Typhimurium (ATCC 14028), Salmonella enterica serovar Choleraesuis (ATCC 7308), Klebsiella pneumoniae (CI 1287) and carbapenemase-2 producing strain of Klebsiella pneumoniae (KPC-2).

Antibacterial assays. Minimal inhibitory concentrations (MICs) were determined in sterilized 96-well plates. Bacteria were grown overnight in Tryptic Soy Broth (TSB) or Luria-Bertani (LB) broth and adjusted to $10^{6} \mathrm{CFU} / \mathrm{ml}$. Next, $100 \mu$ growth medium containing bacteria was added to $100 \mu \mathrm{l}$ culture medium containing the test compound in serial 2 -fold dilutions. Proliferation inhibition was determined by optical density measurements $(620 \mathrm{~nm})$ after incubation overnight at $37^{\circ} \mathrm{C}$.

Chemo-sensitization was assessed similarly, except that bacteria were incubated with a mixture of OAK and antibiotics.

Bactericidal kinetics were determined in a final volume of $1 \mathrm{ml}$, as follows: $100 \mu \mathrm{l}$ of suspension containing bacteria at $10^{6} \mathrm{CFU} / \mathrm{ml}$ were added to $900 \mu$ l of culture medium containing zero or various concentrations of OAK, antibiotic, or their combination. After the specified time-points of exposure $\left(37^{\circ} \mathrm{C}\right.$ under shaking), cultures were subjected to serial 10 -fold dilutions in saline $(0.85 \% \mathrm{NaCl})$ and plated for bacterial enumeration after additional $24 \mathrm{~h}$ incubation. Data were obtained from at least two independent experiments.

Effects of drug delay were assessed similarly, except that bacteria were pre-incubated with OAK for 15 or $30 \mathrm{~min}$, centrifuged and re-suspended in fresh LB containing rifampin and incubated for $3 \mathrm{~h}$ before CFU enumeration.
Membrane depolarization. Measurements were performed with 3,3-

dipropylthiadicarbocyanine iodide $\left(\mathrm{DiSC}_{3} 5\right)$, a lipophilic potentiometric dye ${ }^{46}$. Cells were treated with $2 \mathrm{mM}$ EDTA prior to addition of $\mathrm{DiSC}_{3} 5$ stock solution (final concentration $0.4 \mu \mathrm{M}$ ) and quenching at RT for 20-30 $\mathrm{min}$. $\mathrm{KCl}$ was then added (final concentration $100 \mathrm{mM}$ ), the suspension incubated overnight $\left(4^{\circ} \mathrm{C}\right), 180 \mu \mathrm{l}$ aliquots were placed in black 96 -well plate for $30 \mathrm{~min}$ to allow stabilization of the dye signal, then $20 \mu \mathrm{l}$ of stock solutions of OAK, rifampin, or their combination, were added to obtain the desired final concentrations. Membrane depolarization was monitored by measuring exaction/emission at $620 / 680 \mathrm{~nm}$, respectively, under shaking at $37^{\circ} \mathrm{C}$ (BioTeK Synergy HT Microplate Reader). Data were obtained from at least two independent experiments performed in duplicate.

Outer and inner membrane permeabilization. The mutant E. coli ML-35p was used to monitor the ability of the OAK to perforate/perturb the inner and outer membranes ${ }^{27}$. The assay was performed in sterile 96-well plates in a final volume of $200 \mu \mathrm{l}$. Bacteria were grown overnight in TSB, washed 3 times in sodium phosphate buffer (SPB) $10 \mathrm{mM}, \mathrm{pH}=7.4$ and diluted to $10^{7} \mathrm{CFU} / \mathrm{ml}$ in SPB containing $3 \% \mathrm{TSB}$. Aliquots of this suspension $(100 \mu \mathrm{l})$ were added to $100 \mu \mathrm{l}$ of SPB containing a test compound and either ortho-nitrophenyl- $\beta$-galactoside (ONPG; $2.5 \mu \mathrm{M}$ ) or nitrocefin $(25 \mu \mathrm{M})$. Hydrolysis of ONPG and nitrocefin was monitored by measuring absorbance at 420 or $486 \mathrm{~nm}$, respectively, at various time intervals, with shaking at $37^{\circ} \mathrm{C}$ (BioTeK Synergy HT Microplate Reader). Data were obtained from at least two independent experiments performed in duplicate.

Dansyl-polymyxin binding assay. The affinity of OAKs to LPS from E. coli or from $P$. aeruginosa was studied by displacement of bound dansyl-polymyxin, as described ${ }^{31}$. Briefly, Polymyxin B sulphate was dansylated using dansyl chloride followed by mono dansyl-polymyxin B (DPMB) purification by HPLC. The assay was performed in black 96-well plates containing $180 \mu \mathrm{l}$ of HEPES ( $5 \mathrm{mM}, \mathrm{pH}=7.2), 3 \mu \mathrm{g} / \mathrm{ml} \mathrm{LPS}$, $2 \mu \mathrm{M}$ mono-DPMB and $20 \mu \mathrm{l}$ of OAK or polymyxin solution in the desired concentrations $(0.6-10 \mu \mathrm{M})$. The mixtures were incubated for $1.5 \mathrm{~h}(\mathrm{RT})$. The displacement of DPMB was measured as the corresponding decrease in fluorescence (exaction/emission at 340/485 nm) using a BioTeK Synergy HT Microplate Reader. Data were obtained from at least two independent experiments performed in duplicate.

Hemolytic assay. Hemolytic activity was assessed using fresh Human blood collected into sodium-citrate-containing test tubes, rinsed 3 times in PBS (centrifuged at $200 \times$ $g$ for $2 \mathrm{~min}$ ). Packed cells were re-suspended in PBS resulting in $1 \%$ hematocrit. $50 \mu \mathrm{l}$ of this suspension were added to Eppendorf test tubes containing $200 \mu$ lof test compound solutions (in serial twofold dilutions), PBS alone (for base-line value), or double distilled water (DDW) (for $100 \%$ hemolysis). After $3 \mathrm{~h}$ incubation $\left(37^{\circ} \mathrm{C}\right.$ under shaking), samples were centrifuged at $14000 \times g$ for 2 min and hemolytic activity was assessed as function of hemoglobin leakage by measuring absorbance of $200 \mu \mathrm{l}$ of supernatant at $450 \mathrm{~nm}$.

In-vivo studies. Animal studies were performed using male ICR mice (weight range, $23 \pm 2$ g) obtained from Harlan Laboratories (Rehovot, Israel). Procedures, care and handling of animals were reviewed and approved by Technion Animal Care and Use Committee.

Toxicity. Maximal tolerated dose (MTD) was determined after single-dose subcutaneous (SC) or oral (gavage) administration of OAKs at specified doses using 2 or $10 \mathrm{mice} / \mathrm{compound}$. Animals were inspected for adverse effects during $6 \mathrm{~h}$ by recording motor activity, piloerection, redness in ear lobes, cyanosis, protruding eyeballs, slow or labored breathing, loss of response in the rear leg and convulsions. Mortality was monitored during 7 days thereafter.

Pharmacokinetic study. Drugs blood concentrations were determined by LC-MS using calibrated curves essentially as described ${ }^{5,9}$. Briefly, OAK and/or rifampin were given by SC or oral administration. At specified time intervals mice were euthanized $\left(\mathrm{CO}_{2}\right.$ asphyxiation) and blood samples collected from vena cava $(\mathrm{N}=2 \mathrm{mice} /$ time point). For analysis, samples were centrifuged $(2 \mathrm{~min}, 6000 \times g), 200 \mu \mathrm{l}$ plasma were mixed with $0.5 \mathrm{ml}$ extraction buffer (50\% acetonitrile (ACN): $50 \%$ methanol) incubated $(30 \mathrm{~min}$ on plate shaker at $200 \mathrm{rpm}$, RT), centrifuged $(2 \mathrm{~min}, 14000 \times g)$ and $300 \mu$ supernatant diluted twofold in DDW and analyzed by LC-MS ( $5 \mu \mathrm{l}$ injected to Waters Xevo G2 Tof/ACQUITY UPLC H-Class system). Flow rate, $0.5 \mathrm{ml} / \mathrm{min}$. Run time, $5 \mathrm{~min}$. Mobile phase, ACN/DDW combination containing $0.1 \%$ formic acid using an ACQUITY UPLC BEH column $\left(\mathrm{C}_{18} 1.7 \mu \mathrm{m}\right)$ and eluted with a $0-90 \%$ ACN gradient. Quantification was by MS detection in positive ionization mode using an identical procedure that was performed in mouse whole blood in order to establish standard calibration curves.

Efficacy. Mice were rendered neutropenic by intraperitoneal (IP) injection of cyclophosphamide (150 and $100 \mathrm{mg} / \mathrm{Kg}$ on days 0 and 3, respectively). The procedure was confirmed to result in severe neutropenia by day 4 , at which time infection was induced. The peritonitis-sepsis model was used whereby infection was obtained after IP injection of a logarithmic-phase culture of $K$. pneumoniae $(3 \times$ $10^{7} \mathrm{CFU} /$ mice in $0.3 \mathrm{ml} \mathrm{PBS}$ ). Immediately thereafter, mice were treated orally with rifampin ( $0.25 \mathrm{ml} \mathrm{DDW}$ containing $0.45 \mathrm{mg} /$ mouse), whereas the OAKs were administered subcutaneously, an hour post-inoculation $(0.3 \mathrm{ml}$ PBS containing $0.3 \mathrm{mg} / \mathrm{mouse}$ ). Mice survival was monitored for up to 7 days post-treatment. 
Survival data were obtained from 2 independent experiments $(\mathrm{n}=10 \mathrm{mice} / \mathrm{group} /$ experiment). Statistical analysis was performed using a paired $t$ test were $\alpha$ equals 0.05

1. Torres, J. A., Villegas, M. V. \& Quinn, J. P. Current concepts in antibiotic-resistant gram-negative bacteria. Expert Rev. Anti Infect. Ther. 5, 833-843 (2007).

2. Freire-Moran, L. et al. Critical shortage of new antibiotics in development against multidrug-resistant bacteria-Time to react is now. Drug Resist. Updat. 14, 118-124 (2011).

3. Butler, M. S., Blaskovich, M. A. \& Cooper, M. A. Antibiotics in the clinical pipeline in 2013. J. Antibiot. 66, 571-591 (2013).

4. Kinch, M. S., Patridge, E., Plummer, M. \& Hoyer, D. An analysis of FDA-approved drugs for infectious disease: antibacterial agents. Drug Discov. Today 19, 1283-1287 (2014).

5. Radzishevsky, I. S. et al. Improved antimicrobial peptides based on acyl-lysine oligomers. Nat. biotechnol. 25, 657-659 (2007).

6. Radzishevsky, I. S. et al. Structure-activity relationships of antibacterial acyl-lysine oligomers. Chem. Biol. 15, 354-362 (2008).

7. Livne, L. et al. Design and characterization of a broad -spectrum bactericidal acyllysyl oligomer. Chem. Biol. 16, 1250-1258 (2009).

8. Epand, R. F., Sarig, H., Mor, A. \& Epand, R. M. Cell-wall interactions and the selective bacteriostatic activity of a miniature oligo-acyl-lysyl. Biophys. J. 97, 2250-2257 (2009)

9. Sarig, H. et al. A miniature mimic of host defense peptides with systemic antibacterial efficacy. FASEB J. 24, 1904-1913 (2010).

10. Goldberg, K. et al. Sensitization of gram-negative bacteria by targeting the membrane potential. FASEB J. 27, 3818-3826 (2013).

11. Kaneti, G., Sarig, H., Marjieh, I., Fadia, Z. \& Mor, A. Simultaneous breakdown of multiple antibiotic resistance mechanisms in S. aureus. FASEB J. 27, 4834-4843 (2013).

12. Leive, L. The barrier function of the gram-negative envelope. Ann. N. Y. Acad. Sci. 235, 109-129 (1974)

13. Hancock, R. E. W. Alterations in outer membrane permeability. Annu. Rev. Microbiol. 38, 237-264 (1984).

14. Cirioni, O. et al. Protective effects of the combination of alpha-helical antimicrobial peptides and rifampicin in three rat models of Pseudomonas aeruginosa infection. J. Antimicrob. Chemother. 62, 1332-1338 (2008).

15. Vaara, M. Novel derivatives of polymyxins. J. Antimicrob Chemother. 68, 1213-1219 (2013).

16. Khara, J. S. et al. Anti-mycobacterial activities of synthetic cationic alpha-helical peptides and their synergism with rifampicin. Biomaterials 35, 2032-2038 (2014).

17. Petrosillo, N., Ioannidou, E. \& Falagas, M. E. Colistin monotherapy vs. combination therapy: evidence from microbiological, animal and clinical studies. Clin. Microbiol. Infect. 14, 816-827 (2008).

18. Vaara, M. Agents That Increase the Permeability of the Outer-Membrane. Microbiol. Rev. 56, 395-411 (1992).

19. Jin, D. J. \& Gross, C. A. Mapping and Sequencing of Mutations in the EscherichiaColi Rpob Gene That Lead to Rifampicin Resistance. J. Mol. Biol. 202, 45-58 (1988).

20. Campbell, E. A. et al. Structural mechanism for rifampicin inhibition of bacterial rna polymerase. Cell 104, 901-912 (2001).

21. Hui, J., Gordon, N. \& Kajioka, R. Permeability Barrier to Rifampin in Mycobacteria. Antimicrob. Agents Chemother. 11, 773-779 (1977).

22. Brennan, P. J. \& Nikaido, H. The envelope of mycobacteria. Annu. Rev. Biochem. 64, 29-63 (1995).

23. Sarig, H., Rotem, S., Ziserman, L., Danino, D. \& Mor, A. Impact of self-assembly properties on antibacterial activity of short acyl-lysine oligomers. Antimicrob. Agents Chemother. 52, 4308-4314 (2008).

24. Optimization of the rifampin dosage to improve the therapeutic efficacy in tuberculosis treatment using a murine model. Am. J. Respir. Crit. Care Med. 187, 1127-1134 (2013).

25. Lyons, M. A., Reisfeld, B., Yang, R. S. \& Lenaerts, A. J. A physiologically based pharmacokinetic model of rifampin in mice. Antimicrob. Agents Chemother. 57, 1763-1771 (2013).

26. Westerhoff, H. V., Juretic, D., Hendler, R. W. \& Zasloff, M. Magainins and the disruption of membrane-linked free-energy transduction. Proc. Natl. Acad. Sci. U.S.A. 86, 6597-6601 (1989).

27. Lehrer, R. I., Barton, A. \& Ganz, T. Concurrent assessment of inner and outer membrane permeabilization and bacteriolysis in E. coli by multiple-wavelength spectrophotometry. J. Immunol. Methods 108, 153-158 (1988).

28. Storm, D. R., Rosenthal, K. S. \& Swanson, P. E. Polymyxin and related peptide antibiotics. Annu. Rev. Biochem. 46, 723-763 (1977).

29. Daugelavicius, R., Bakiene, E. \& Bamford, D. H. Stages of polymyxin B interaction with the Escherichia coli cell envelope. Antimicrob. Agents Chemother. 44, 2969-2978 (2000).

30. Velkov, T., Thompson, P. E., Nation, R. L. \& Li, J. Structure--activity relationships of polymyxin antibiotics. J. Med. Chem. 53, 1898-1916 (2010).
31. Moore, R. A., Bates, N. C. \& Hancock, R. E. W. Interaction of Polycationic Antibiotics with Pseudomonas-Aeruginosa Lipopolysaccharide and Lipid-a Studied by Using Dansyl-Polymyxin. Antimicrob. Agents Chemother. 29, 496-500 (1986).

32. Ellard, G. A. et al. The Bioavailability of Isoniazid, Rifampin, and Pyrazinamide in 2 Commercially Available Combined Formulations Designed for Use in the Short-Course Treatment of Tuberculosis. Am. Rev. Respir. Dis. 133, 1076-1080 (1986).

33. Gordin, F. et al. Rifampin and pyrazinamide vs isoniazid for prevention of tuberculosis in HIV-infected persons: an international randomized trial. Terry Beirn Community Programs for Clinical Research on AIDS, the Adult AIDS Clinical Trials Group, the Pan American Health Organization, and the Centers for Disease Control and Prevention Study Group. JAMA 283, 1445-1450 (2000).

34. Eliopoulos, G. M. \& Eliopoulos, C. T. Antibiotic combinations: should they be tested? Clin. Microbiol. Rev. 1, 139-156 (1988).

35. Tamma, P. D., Cosgrove, S. E. \& Maragakis, L. L. Combination therapy for treatment of infections with gram-negative bacteria. Clin. Microbiol. Rev. 25, 450-470 (2012)

36. Nikaido, H. Molecular Basis of Bacterial Outer Membrane Permeability Revisited. Microbiol. Mol. Biol. Rev. 67, 593-656 (2003).

37. Vaara, M. et al. Novel polymyxin derivatives carrying only three positive charges are effective antibacterial agents. Antimicrob. Agents Chemother. 52, 3229-3236 (2008).

38. Vaara, M., Siikanen, O., Apajalahti, J., Frimodt-Moller, N. \& Vaara, T. Susceptibility of carbapenemase-producing strains of Klebsiella pneumoniae and Escherichia coli to the direct antibacterial activity of NAB739 and to the synergistic activity of NAB7061 with rifampicin and clarithromycin. J. Antimicrob. Chemother. 65, 942-945 (2010).

39. Kalita, A., Verma, I. \& Khuller, G. K. Role of human neutrophil peptide-1 as a possible adjunct to antituberculosis chemotherapy. J. Infect. Dis. 190, 1476-1480 (2004).

40. Scott, R. W., DeGrado, W. F. \& Tew, G. N. De novo designed synthetic mimics of antimicrobial peptides. Curr. Opin. Biotechnol. 19, 620-627 (2008).

41. Rotem, S. \& Mor, A. Antimicrobial peptide mimics for improved therapeutic properties. Biochim. Biophys. Acta 1788, 1582-1592 (2009).

42. Vlieghe, P., Lisowski, V., Martinez, J. \& Khrestchatisky, M. Synthetic therapeutic peptides: science and market. Drug Discov. Today 15, 40-56 (2010).

43. Marr, A. K., Gooderham, W. J. \& Hancock, R. E. W. Antibacterial peptides for therapeutic use: obstacles and realistic outlook. Curr. Opin. Pharmacol. 6 , $468-472$ (2006)

44. Schuerholz, T., Brandenburg, K. \& Marx, G. Antimicrobial peptides and their potential application in inflammation and sepsis. Crit. Care 16, 207 (2012).

45. Fields, G. B. \& Noble, R. L. Solid-Phase Peptide-Synthesis Utilizing 9Fluorenylmethoxycarbonyl Amino-Acids. Int. J. Pept. Prot. Res. 35, 161-214 (1990).

46. Zhang, L., Dhillon, P., Yan, H., Farmer, S. \& Hancock, R. E. Interactions of bacterial cationic peptide antibiotics with outer and cytoplasmic membranes of Pseudomonas aeruginosa. Antimicrob. Agents Chemother. 44, 3317-3321 (2000).

\section{Acknowledgments}

This work was supported by the Israel Science Foundation (grant 909/12) and in part by the Russell Berrie Nanotechnology Institute (Technion).

\section{Author contributions}

J.J. synthesized reagents, performed research, analyzed data, wrote the paper; F.Z. performed research (in-vivo blood concentrations), analyzed data; G.K. performed research (in-vivo toxicity and efficacy experiments), analyzed data; K.G. performed research (part of the antibacterial assays); A.M. designed the experiments, analyzed data, wrote the paper. All authors discussed the results and commented on the manuscript.

\section{Additional information}

Supplementary information accompanies this paper at http://www.nature.com/ scientificreports

Competing financial interests: The authors declare no competing financial interests.

How to cite this article: Jammal, J., Zaknoon, F., Kaneti, G., Goldberg, K. \& Mor, A Sensitization of Gram-negative bacteria to rifampin and OAK combinations. Sci. Rep. 5 , 9216; DOI:10.1038/srep09216 (2015).

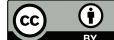

This work is licensed under a Creative Commons Attribution 4.0 International License. The images or other third party material in this article are included in the article's Creative Commons license, unless indicated otherwise in the credit line; if the material is not included under the Creative Commons license, users will need to obtain permission from the license holder in order to reproduce the material. To view a copy of this license, visit http://creativecommons.org/licenses/by/4.0/ 